\title{
Therapeutic response to a novel enzyme-targeting radiosensitization treatment (KORTUC II) for residual lesions in patients with stage IV primary breast cancer, following induction chemotherapy with epirubicin and cyclophosphamide or taxane
}

\author{
NOBUTAKA AOYAMA $^{1}$, YASUHIRO OGAWA ${ }^{2}$, MIKI YASUOKA ${ }^{1}$, HITOMI IWASA $^{1}$, KANA MIYATAKE $^{1}$, \\ RIKA YOSHIMATSU $^{1}$, TOMOAKI YAMANISHI ${ }^{1}$, NORIHIKO HAMADA ${ }^{1}$, TAIJI TAMURA ${ }^{1}$, \\ KANA KOBAYASHI $^{1}$, YORIKO MURATA ${ }^{1}$, TAKUJI YAMAGAMI ${ }^{1}$ and MITSUHIKO MIYAMURA ${ }^{3}$ \\ ${ }^{1}$ Department of Diagnostic Radiology and Radiation Oncology, Kochi Medical School, \\ Kochi University, Kochi 783-8505; ${ }^{2}$ Hyogo Prefectural Kakogawa Medical Center, Kakogawa, Hyogo 675-8555; \\ ${ }^{3}$ Department of Pharmacy, Kochi Medical School, Kochi University, Kochi 783-8505, Japan
}

Received August 11, 2015; Accepted August 25, 2016

DOI: $10.3892 / 01.2016 .5456$

\begin{abstract}
Linac-based radiotherapy has a negligible effect on the majority of advanced neoplasms. Therefore, a novel radiosensitization treatment Kochi Oxydol Radiation Therapy for Unresectable Carcinomas II (KORTUC II), which utilizes hydrogen peroxide and sodium hyaluronate was developed. The effectiveness of KORTUC II for the treatment of chemotherapy-resistant supraclavicular lymph node metastases and recurrent breast cancers has previously been demonstrated. The present study evaluated the safety and efficacy of KORTUC II in patients with stage IV primary breast cancer. Seven patients (age range, 36-65 years) were enrolled. All patients received induction chemotherapy prior to KORTUC II treatment and underwent positron emission tomography-computed tomography (PET-CT) examinations prior to and 2-7 months following KORTUC II treatment, and every six months thereafter where possible. The radiotherapy regimen (x-ray irradiation) was 2.75 gray (Gy)/fraction, 5 fractions/week for 16-18 fractions with a total radiation dose of 44-49.5 Gy. Administration of the KORTUC II agent (3-6 $\mathrm{ml}: 3 \mathrm{ml}$ for a lesion $<3 \mathrm{~cm}$ in diameter and $6 \mathrm{ml}$ for a lesion $\geq 3 \mathrm{~cm}$ ) was initiated from the sixth radiotherapy fraction, and was conducted twice a week under ultrasonographic guidance. The therapeutic effects were evaluated by PET-CT examinations prior to and
\end{abstract}

Correspondence to: Dr Nobutaka Aoyama, Department of Diagnostic Radiology and Radiation Oncology, Kochi Medical School, Kochi University, 203 Kohasu, Oko-cho, Nankoku, Kochi 783-8505, Japan

E-mail: jm-aoyama_nobutaka@kochi-u.ac.jp

Key words: hydrogen peroxide, sodium hyaluronate, Kochi Oxydol Radiation Therapy for Unresectable Carcinomas II, radiosensitizer, primary breast cancer stage IV, ultrasonographic guidance following KORTUC II treatment. Of the seven lesions from the seven patients, five exhibited complete responses, two exhibited partial responses and none exhibited stable disease or progressive disease. The overall survival rate was determined to be $100 \%$ at 1 and $86 \%$ at 2 years post-treatment. The mean duration of follow-up by December 2014 was 51 months. The results of the PET-CT studies indicated that KORTUC II treatment demonstrated marked therapeutic effects with satisfactory treatment outcomes and acceptable adverse effects.

\section{Introduction}

Previously metastasis was a predictor of patient mortality; however, advances in the current understanding of cancer biology have enabled the cure or control of various malignancies and improved the prognosis and quality of life for patients $(1,2)$. Surgery and radiotherapy are used for local control and chemotherapy is used for systemic control (1-3). Through the application of these treatments, certain types of cancer may be cured; however, various specific types of cancer contain numerous hypoxic cancer cells and antioxidant enzymes that may confer resistance to radiotherapy (1-3). In addition to increasing tissue oxygen concentrations, it is important to inactivate antioxidant enzymes, including peroxidase and catalase, which protect cancer cells from oxidative stress (1-10). Hydrogen peroxide is able to inactivate antioxidant enzymes and produce oxygen when applied topically to cancer tissues (1-3). By adding hyaluronic acid to hydrogen peroxide the decomposition of hydrogen peroxide is delayed, and a high oxygen concentration is maintained in the cancer tissues for over $24 \mathrm{~h}$ (1-3). As reported in our previous studies $(5,9,10)$, a novel radiosensitizer, Kochi Oxydol Radiation Therapy for Unresectable Carcinomas II (KORTUC II), was developed for the treatment of cancers that contain numerous hypoxic cancer cells and antioxidant enzymes. The components of KORTUC II are sodium hyaluronate $0.83 \% \mathrm{w} / \mathrm{v}$ and hydrogen peroxide $0.5 \% \mathrm{w} / \mathrm{v}$. The concept 
Table I. Patient clinical and therapeutic data.

\begin{tabular}{|c|c|c|c|c|c|c|c|}
\hline Pt. & $\begin{array}{l}\text { Age } \\
(y)\end{array}$ & $\begin{array}{l}\text { Metastatic } \\
\text { area }\end{array}$ & $\begin{array}{c}\text { Induction } \\
\text { chemotherapy }\end{array}$ & $\begin{array}{c}\text { Treatment area } \\
\text { (KORTUC II field) }\end{array}$ & $\begin{array}{c}\text { FDG } \\
\text { accumulation }\end{array}$ & $\begin{array}{c}\text { Tumor } \\
\text { size }(\mathrm{mm})\end{array}$ & $\begin{array}{c}\text { Therapeutic } \\
\text { effect }\end{array}$ \\
\hline 1 & 63 & Bone, lung and lymph node & PTX x 15 & Left breast & $5.6 \rightarrow \mathrm{D}^{\mathrm{a}}$ & $14 \rightarrow 10$ & PR \\
\hline 2 & 57 & Lymph node and skin & FEC x 8 & Left breast & $7.7 \rightarrow \mathrm{D}^{\mathrm{a}}$ & $28 \rightarrow \mathrm{D}^{\mathrm{a}}$ & $\mathrm{CR}^{\mathrm{b}}$ \\
\hline 3 & 65 & Bone, lung and lymph node & $\mathrm{EC} \times 6$ & Left breast & $11.2 \rightarrow \mathrm{D}^{\mathrm{a}}$ & $15 \rightarrow 3$ & $\mathrm{CR}^{\mathrm{b}}$ \\
\hline 4 & 58 & Lymph node and skin & $\mathrm{EC} \times 3$ & Right breast & $8.6 \rightarrow \mathrm{D}^{\mathrm{a}}$ & $28 \rightarrow 14$ & $\mathrm{CR}^{\mathrm{b}}$ \\
\hline 5 & 55 & Lung & $\mathrm{EC} \times 3$ & Left breast & $6.2 \rightarrow 2.2$ & $28 \rightarrow 22$ & PR \\
\hline 6 & 36 & Lymph node & FEC x 4 and PTX x 12 & Right breast & No data $\rightarrow 2.5$ & No data $\rightarrow \mathrm{D}^{\mathrm{a}}$ & $\mathrm{CR}^{\mathrm{b}}$ \\
\hline 7 & 51 & Bone & EC x 9 and TXT x 6 & Left breast & $5.1 \rightarrow \mathrm{D}^{\mathrm{a}}$ & $23 \rightarrow \mathrm{D}^{\mathrm{a}}$ & $\mathrm{CR}^{\mathrm{b}}$ \\
\hline
\end{tabular}

${ }^{a} \mathrm{D}$ was defined as the disappearance of cancer shadows following CT examination. ${ }^{\mathrm{b}}$ The criteria for CR was the dissipation of FDG accumulation as determined by PET-CT or the tumor lesion as determined by CT. RT field, radiation therapy field; CR, complete response; PR, partial response; D, disappearance; X, x-ray; E, electron beam; PTX, paclitaxel; EC, epirubicin and cyclophosphamide; FEC, fluorouracil and epirubicin and cyclophosphamide; TXT, docetaxel hydrate; Pt, patient; KORTUC II, Kochi Oxydol Radiation Therapy for Unresectable Carcinomas II; FDG, fluorodeoxyglucose; PET-CT, positron emission tomography-computed tomography.

\section{Malignant tumor}

- Many antioxidative enzymes

around the tumor

- Limited oxygen

- Hypoxic lesion

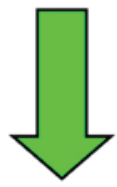

$$
\begin{aligned}
& \text { New radiosensitizer KORTUC II (sodium } \\
& \text { hyaluronate containing hydrogen peroxide }
\end{aligned}
$$

\section{Malignant tumor}

\section{- Few antioxidative enzymes around the tumor \\ - Plentiful oxygen \\ - Hyperoxic lesion}

Radioresistant

Figure 1. The mechanism of action for the novel radiosensitizer KORTUC II. Antioxidant enzymes in the tumors are inactivated and plentiful oxygen is produced; in this way, radioresistant cancers can be made radiosensitive. KORTUC II, Kochi Oxydol Radiation Therapy for Unresectable Carcinomas II.

of KORTUC II is to transform radioresistant cancer into radiosensitive cancer $(9,10)$. Following KORTUC II therapy, hypoxic and radioresistant cancer cells become hyperoxic and radiosensitive (Figure 1). In our previous studies, the efficacy of KORTUC II in the treatment of supraclavicular lymph node metastates and recurrent breast cancers was demonstrated in humans $(9,10)$. The aim of the current study is to evaluate the safety and effectiveness of KORTUC II in patients with stage IV primary breast cancer, following induction chemotherapy with epirubicin combined with cyclophosphamide and paclitaxel or docetaxel.

\section{Materials and methods}

KORTUC II formulation. Hyaluronic acid preparation $(2.5 \mathrm{ml})$ with $1 \% \mathrm{w} / \mathrm{v}$ sodium hyaluronate (ARTZ Dispo ${ }^{\circledR}$; Seikagaku Corporation, Tokyo, Japan) was present in each dose. This was composed of $25 \mathrm{mg}$ sodium hyaluronate, $2.5 \mathrm{mg}$ L-methionine

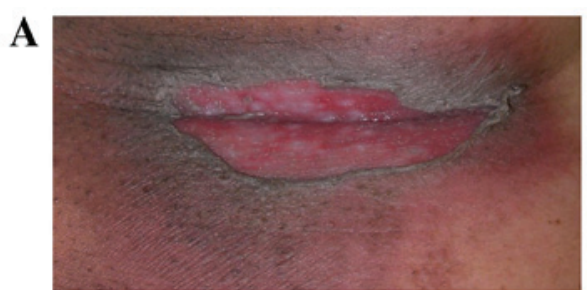

B

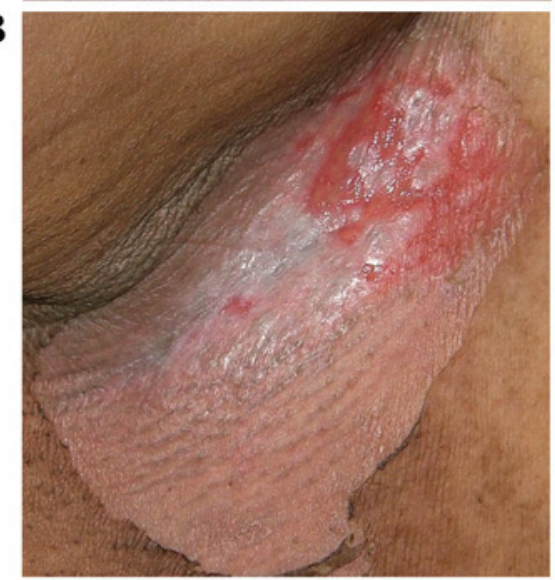

C

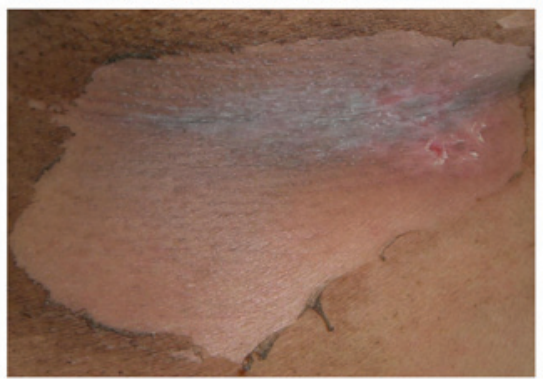

Figure 2. Representative complications observed in the treated tissues of patient number 4 (58-year-old female with stage IV primary breast cancer). The patient was selected due to the presence of characteristic complications. (A) 10 days following the KORTUC II treatment, erosion surrounded by ulcers was observed at the right axilla. Gentamicin sulfate ointment was applied to treat the erosion and clobetasol propionate ointment was applied for the red spots. (B) 15 days following KORTUC II treatment, the erosion and the red spots are markedly improved. (C) 20 days following KORTUC II treatment. Re-epithelialization was observed at the lesion site and recurrence of the lesion was not observed. KORTUC II, Kochi Oxydol Radiation Therapy for Unresectable Carcinomas II. 
Table II. Patient treatment outcomes.

\begin{tabular}{lcrr}
\hline Outcome & 1 year & 2 years & 3 years \\
\hline Overall survival rate & $100 \%(7 / 7)$ & $86 \%(6 / 7)$ & $71 \%(5 / 7)$ \\
Local control rate & $100 \%(7 / 7)$ & $100 \%(6 / 6)$ & $100 \%(5 / 5)$ \\
Disease-free survival rate & $86 \%(6 / 7)$ & $50 \%(3 / 6)$ & $40 \%(2 / 5)$ \\
\hline
\end{tabular}
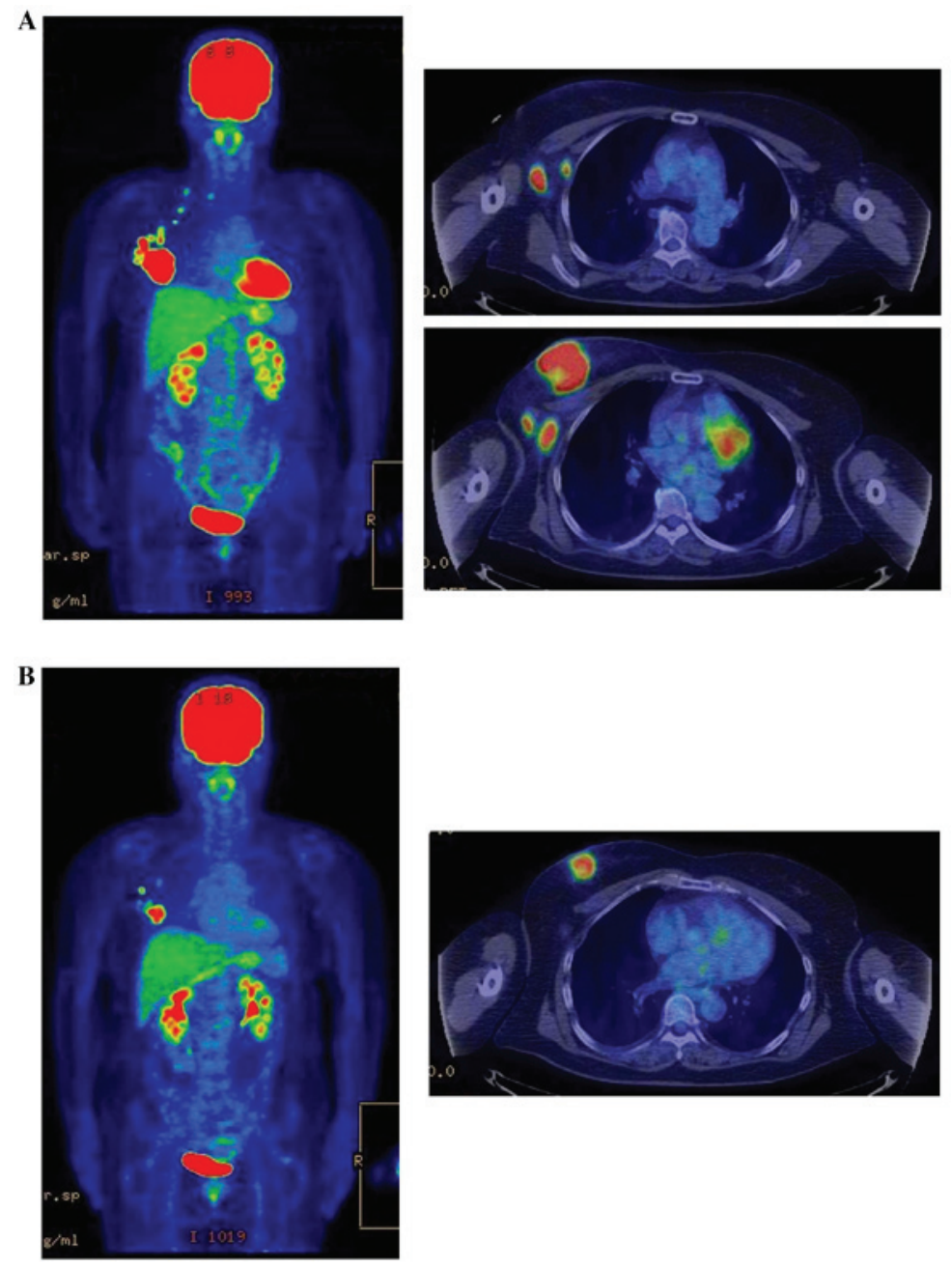

Figure 3. Therapeutic response following KORTUC II treatment as evaluated by PET-CT examination of patient number 4 (58-year-old female with stage IV primary breast cancer). (A) PET-CT prior to induction chemotherapy with epirubicin and cyclophosphamide. Numerous lymph node and skin metastases are depicted. (B) PET-CT prior to KORTUC II treatment. With induction chemotherapy, FDG accumulation in the right breast and right axilla improved and the skin metastases disappeared. KORTUC II, Kochi Oxydol Radiation Therapy for Unresectable Carcinomas II; PET-CT, positron emission tomography-computed tomography; FDG, fluorodeoxyglucose.

(Kaken Pharmaceutical Co.,Ltd., Tokyo, Japan), sodium chloride, potassium phosphate, crystalline sodium dihydrogen phosphate and an isotonizing agent, sodium hyaluronate (Kaken Pharmaceutical Co., Ltd.). The preparation was a colorless, transparent, viscous and aqueous solution with a $\mathrm{pH}$ of 6.8-7.8, a specific osmotic pressure of 1.0-1.2 (relative to physiological saline) and an average molecular weight of 0.6-1.2 million. Immediately prior to administration, $0.5 \mathrm{ml}$ hydrogen peroxide $3 \% \mathrm{w} / \mathrm{v}$ solution (Oxydol; Ken-ei Pharmaceutical Co.,Ltd., Osaka, Japan) was added to the solution. The final solution of the radiosensitizer had a sodium hyaluronate concentration of $\sim 0.83 \%$ and a hydrogen peroxide concentration of $\sim 0.5 \%$. The radiosensitizer solution was the same as the solution administered for the treatment of chemotherapy-resistant supraclavicular lymph node metastates and recurrent breast cancers in our previous studies $(9,10)$.

The recruitment of patients for the present study was conducted between November 2006 and January 2011 at the Kochi Medical School Hospital (Kochi, Japan). The institutional ethics committee of Kochi University approved the use of KORTUC II for the treatment of patients with stage IV primary breast cancer. Seven patients with stage IV primary breast cancer were enrolled in the current study and provided written, informed consent. The criteria for case selection included a patient age of 20-80 years, and the patient and 

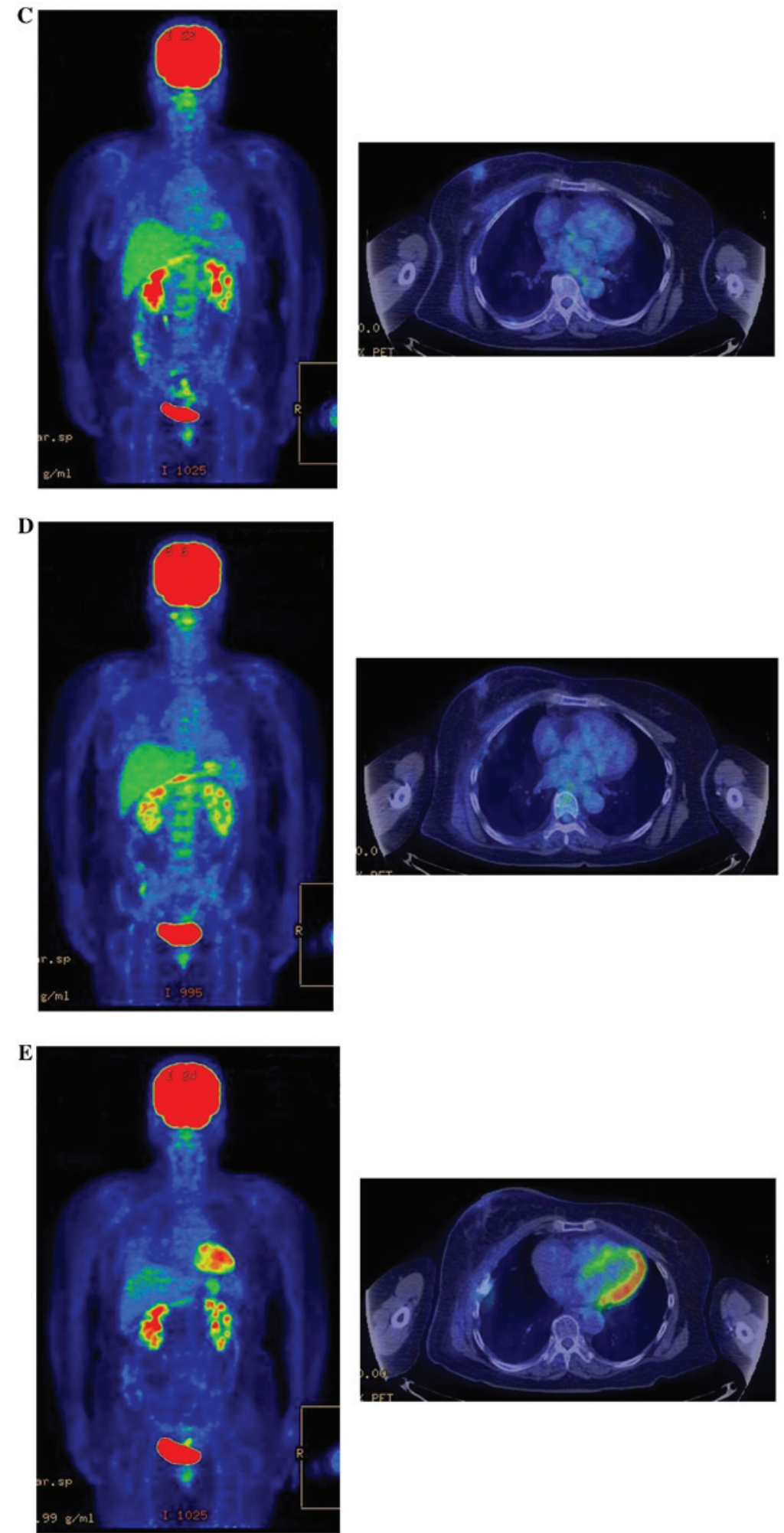

Figure 3. Continued. (C) Four months following KORTUC II treatment. FDG accumulation in the left breast and in the chest disappeared. (D) PET-CT seven months following KORTUC II treatment. FDG accumulation had not recurred on the PET-CT scan conducted (E) 16 months following KORTUC II treatment. KORTUC II, Kochi Oxydol Radiation Therapy for Unresectable Carcinomas II; PET-CT, positron emission tomography-computed tomography; FDG, fluorodeoxyglucose.

their families had opted for the KORTUC II treatment. The ages of the patients ranged from 36-65 years (mean average age, 56 years). Localized management of the lesions was determined to be problematic using regular chemotherapy or radiotherapy. Prior to and following KORTUC II treatment, chemotherapy including epirubicin (Nippon Kayaku, Tokyo, Japan), cyclophosphamide (Shionogi \& Co.,Ltd., Osaka, Japan), fluorouracil (Kyowa Hakko Kirin Co., Ltd., Tokyo, Japan), epirubicin combined with cyclophosphamide, or docetaxel hydrate (Elmed Eisai Co.,Ltd., Tokyo, Japan) was administered 

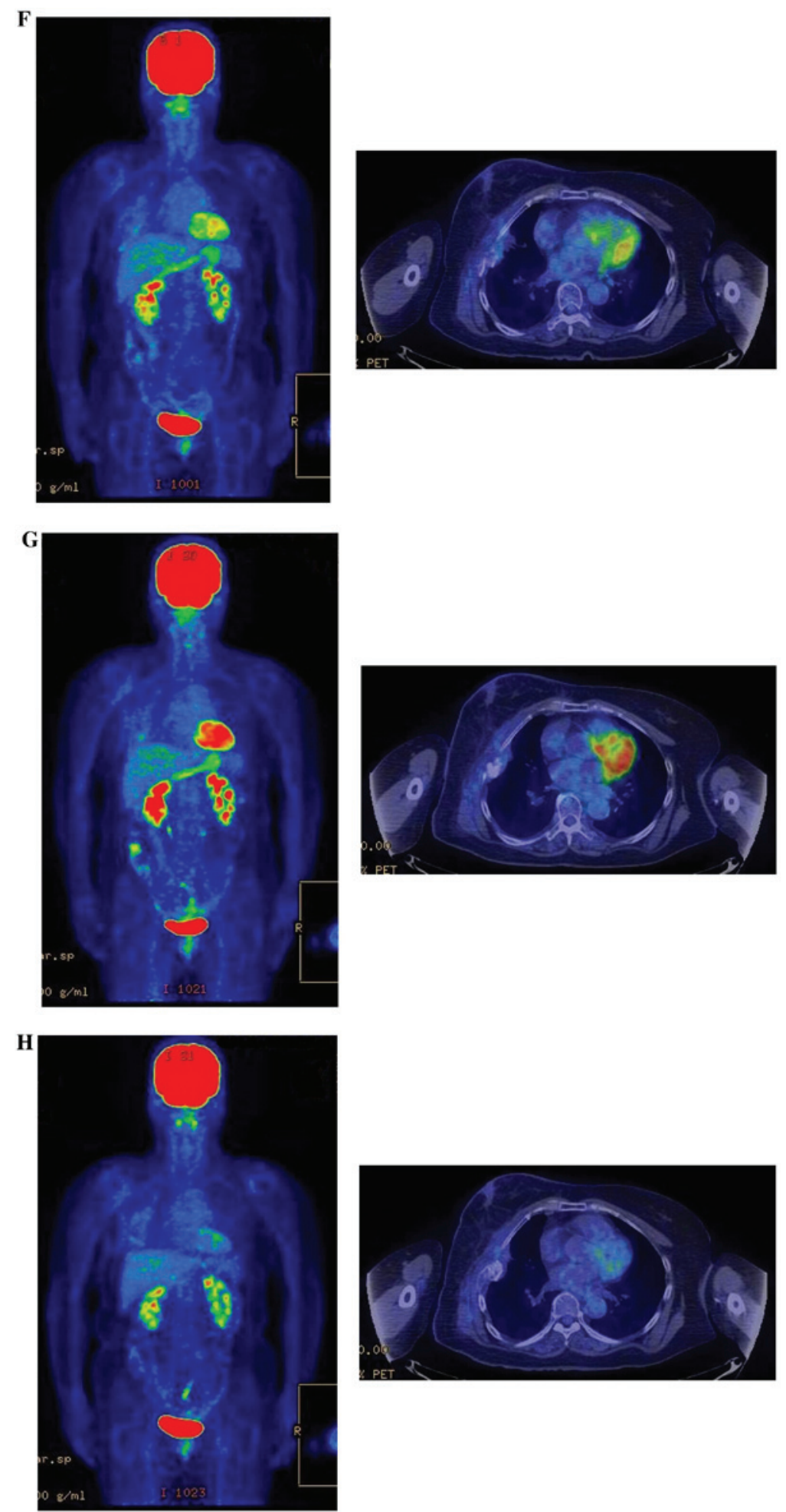

Figure 3. Continued. PET-CT scans conducted (F) 21 months, (G) 26 months and (H) 32 months following KORTUC II treatment. KORTUC II, Kochi Oxydol Radiation Therapy for Unresectable Carcinomas II; PET-CT, positron emission tomography-computed tomography.

to prevent disease progression. The numbers of cycles of chemotherapy prior to KORTUC II therapy are shown in Table I. Combinations of systemic chemotherapy were selected according to updated guidelines for breast cancer treatment.

KORTUC II treatment was administered for the local control of breast cancer and chemotherapy was performed for systemic control. The radiotherapy regimen consisted of $2.75 \mathrm{~Gy} /$ fraction, 5 fractions/week for a total of 16-18 fractions and a total radiation dose of 44-49.5 Gy. For two patients (designated 6 and 7), boost irradiation (3 Gy/fraction, 3 fractions) was administered to control the site of the primary lesions; irradiation by X-ray for the target lesion was performed by tangential irradiation. The energy level of the $\mathrm{X}$-ray was $4 \mathrm{MV}$, and the energy level of the electron beam was $15 \mathrm{MeV}$. The KORTUC II agent was composed of $2.5 \mathrm{ml}$ $1 \% \mathrm{w} / \mathrm{v}$ sodium hyaluronate and $0.5 \mathrm{ml} \mathrm{3 \%} \mathrm{w} / \mathrm{v}$ hydrogen 

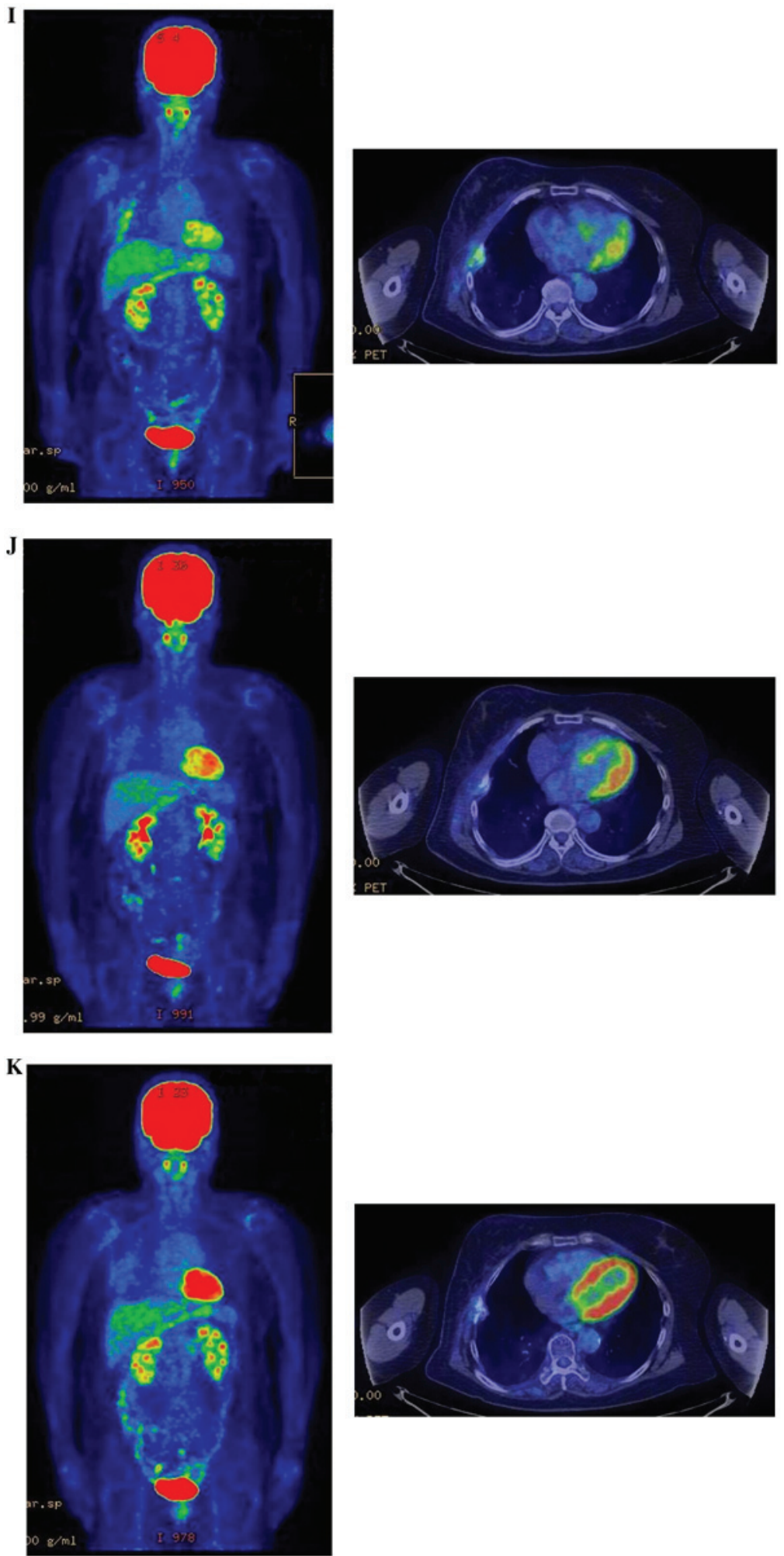

Figure 3. Continued. PET-CT scans conducted (I) 38 months, (J) 49 months and (K) 64 months following KORTUC II treatment. KORTUC II, Kochi Oxydol Radiation Therapy for Unresectable Carcinomas II; PET-CT, positron emission tomography-computed tomography.

peroxide. The administration of 3-6 $\mathrm{ml}$ KORTUC II was initiated following the sixth radiation fraction and performed twice a week under ultrasonographic guidance in order to maintain a high oxygen concentration in the cancerous tissues for $48 \mathrm{~h}$ based on our previous experimental and studies (1-10). The volume of the KORTUC II administered to each patient was adjusted according to the respective tumor diameter evaluated based on imaging modalities such as ultrasonographic studies and/or computed tomography (5). The total number of injections/patient was 5-6. The clinical features and therapeutic effects observed in each patient are presented in Table I.

Assessment of the therapeutic response to KORTUC II treatment. The majority of the patients included in the current 


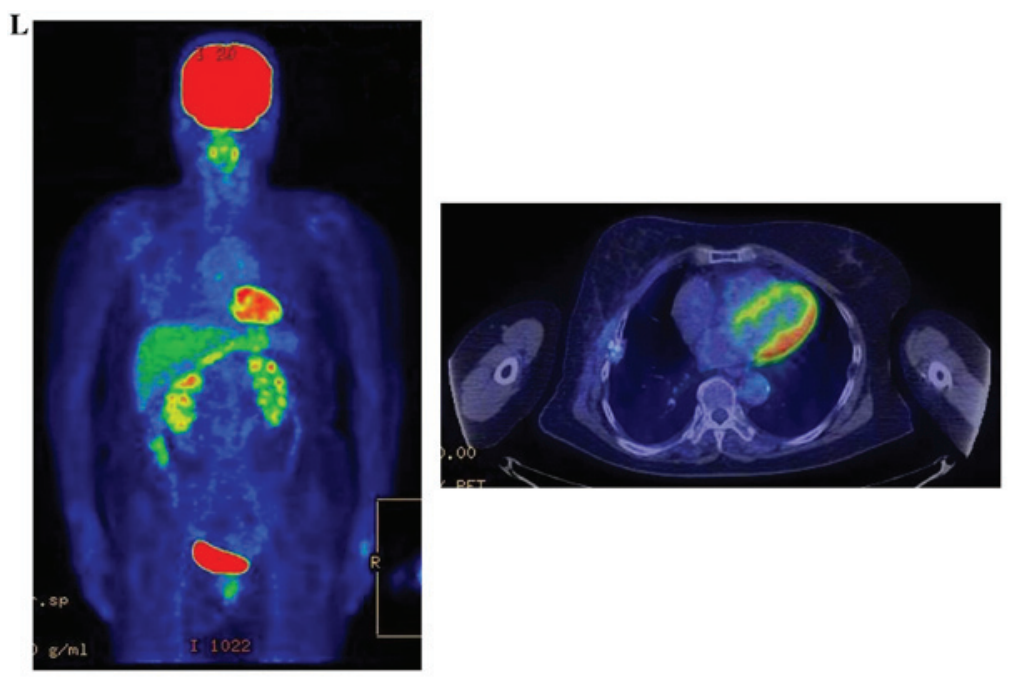

Figure 3. Continued. PET-CT scan conducted (L) 76 months following KORTUC II treatment. FDG accumulation and recurrence of metastasis were not observed during follow-up. Prior to treatment, the size of the right breast tumor was $28 \mathrm{~mm}$ and the SUVmax of FDG accumulation was 8.6. The target lesion and the FDG accumulation had disappeared four months following KORTUC II treatment, as determined by a PET-CT scan. The therapeutic effect was determined to be a complete response in patient number 4. KORTUC II, Kochi Oxydol Radiation Therapy for Unresectable Carcinomas II; PET-CT, positron emission tomography-computed tomography; FDG, fluorodeoxyglucose; SUVmax, max value of the standardized uptake value.

study underwent positron emission tomography-computed tomography (PET-CT) examinations prior to, and 1-7 months following, KORTUC II treatment. The therapeutic effects were evaluated by comparison of the pre-treatment and post-treatment PET-CT scans of the local tissues subjected to KORTUC II therapy. The patients subsequently underwent PET-CT examinations every six months when possible for at least three years, following the conclusion of KORTUC II treatment. The final therapeutic response of the lesion was assessed according to the Revised Response Evaluation Criteria in Solid Tumors guidelines (version 1.1) and patient follow-ups and tumor assessments were performed once a month following KORTUC II therapy. Each patient was assigned a toxicity grade using the National Institutes of Health Common Toxicity Criteria $(9,10)$. To evaluate the feasibility of KORTUC II treatment, all treatment-associated complications were assessed according to the Common Terminology Criteria for Adverse Events (CTCAE; version 4.0) $(9,10)$. Patient follow-ups were conducted for $\geq 15$ months (1-3).

\section{Results}

KORTUC II treatment was completed with tolerable adverse effects. Four patients (57\%) exhibited the acute phase complications of local erosion or ulceration in the treated tissues and required professional dermatological treatment [patient (Pt.)2, Pt.3, Pt.4 and Pt.5]. These complications were considered to be causally associated with tumor shrinkage induced by KORTUC II treatment. The aforementioned patients were determined to have CTCAE grade IV complications. Three patients $(43 \%)$ experienced soreness and depilation in the treated tissues (Pt.1, Pt.6 and Pt.7) and were determined to have CTCAE grade II complications. All the complications exhibited by the patients were cured by local treatment and are presented in Fig. 2. None of the patients were observed to develop chronic complications during the present study.

Of the seven patients, five $(71 \%)$ exhibited a complete response, two (29\%) demonstrated a partial response and none of the patients exhibited stable or progressive disease; thus, the response rate was $100 \%$. The overall survival rate was $100 \%$ at 1 year, 86\% (6/7) at 2 years and $71 \%(5 / 7)$ at 3 years. The local control rate was $100 \%$ at 1 year (7/7), 2 years $(6 / 6)$ and 3 years $(5 / 5)$. The disease-free survival rate was $86 \%(6 / 7)$ at 1 year, $50 \%(3 / 6)$ at 2 years and $40 \%(2 / 5)$ at 3 years (Table II).

The treatment outcomes were satisfactory and the adverse effects were determined to be within an acceptable range. Representative PET-CT examinations are presented in Fig. 3. Although new metastatic lesions were detected in four patients during follow-up, overall the lesions were ameliorated by the appropriate treatment. The mean follow-up period by December 2014 was 51 months; four patients have succumbed to the disease at the time of writing.

\section{Discussion}

Improvements in diagnostic methods have facilitated the earlier detection of numerous types of primary cancer, recurrent cancer and metastases, and previous advances in chemotherapy have been notable. For metastatic or unresectable cancer, combination chemotherapy and radiotherapy (chemoradiotherapy) is typically administered with good therapeutic outcomes (11-21). The results of our previous studies $(9,10)$ regarding the use of KORTUC II for the treatment of supraclavicular lymph node metastates and recurrent breast cancers indicated comparable efficacy to treatment with chemoradiotherapy. Although the present study utilized alternative evaluation and timing methods, the effect of KORTUC II for the treatment of local lesions in patients with stage IV breast cancer, following induction chemotherapy, revealed similar treatment outcomes compared with chemoradiotherapy (11-21). The response rate $(100 \%)$ and the overall survival rate at 1 year (100\%), 2 years $(85 \%)$ and 3 years $(71 \%)$ were good, and the treatment regimen was well tolerated. Certain patients exhibited severe side effects in the treated tissues, which was possibly due to tumor shrinkage induced by KORTUC II. Although metastasis was 
observed during patient examinations following the conclusion of the treatment, the majority of the lesions were improved. The results indicate that KORTUC II treatment outcomes are satisfactory with adverse effects within an acceptable range, particularly for stage IV primary breast cancer following induction chemotherapy. Though the numbers of the patients treated with KORTUC II in the individual studies are small, good therapeutic effects of KORTUC II have also been reported in other studies (1-8). Therefore, KORTUC II may be a novel therapeutic treatment for patients with breast cancer $(3,4,6,8)$. KORTUC II consists of sodium hyaluronate $0.83 \% \mathrm{w} / \mathrm{v}$ and hydrogen peroxide $0.5 \% \mathrm{w} / \mathrm{v}$, which are inexpensive and readily available. The mechanism of action of KORTUC II is simple $(9,10)$, involving inactivation of peroxidase/catalase and production of oxygen in the target tumor tissue simultaneously, and deep lesions are accessible to treatment through the use of a Cathelin needle to administer the radiosensitizer under ultrasonographic guidance.

Therefore, the novel radiosensitizer KORTUC II may be used for the treatment of certain types of cancer. However, the number of patients currently and previously treated with KORTUC II, and the respective follow-up periods, is too small for a definitive conclusion. Further randomized clinical trials with a larger sample size are required to establish the therapeutic efficacy of KORTUC II.

\section{Acknowledgements}

The authors would like to thank Forte Science Communications, Tokyo, Japan, for their editorial assistance. This study was partially supported by a Grant-in-Aid for Scientific Research from the Japanese Ministry of Education, Culture, Sports, Science and Technology (grant no. 25461916).

\section{References}

1. Ogawa Y, Kubota K, Ue H, Nishioka A, Kariya S, Yokota N, Sasaki T, Suzuki K, Nakatani K, Yamanishi T, et al: Development and clinical application of a new radio sensitizer containing hydrogen peroxide and hyaluronic acid sodium for topical tumor injection - a new enzyme-targeting radiosensitization treatment, KORTUC II (Kochi Oxydol-Radiation Therapy for Unresectable Carcinomas, Type II). Strahlenther Onkol 183: 100-101, 2007.

2. Ogawa Y, Ue H, Tsuzuki K, Tadokoro M, Miyatake K, Sasaki T, Yokota N, Hamada N, Kariya S, Hitomi J, et al: New radiosensitization treatment (KORTUC I) using hydrogen peroxide solution-soaked gauze bolus for unresectable and superficially exposed neoplasms. Oncol Rep 19: 1389-1394, 2008.

3. Ogawa Y, Kubota K, Ue H, Kataoka Y, Tadokoro M, Miyatake K, Tsuzuki K, Yamanishi T, Itoh S, Hitomi J, et al: Phase I study of a new radiosensitizer containing hydrogen peroxide and sodium hyaluronate for topical tumor injection: A new enzyme-targeting radiosensitization treatment, Kochi Oxydol-Radiation Therapy for Unresectable Carcinomas, Type II (KORTUC II). Int J Oncol 34: 609-618, 2009

4. MiyatakeK,KubotaK,Ogawa Y,HamadaN,Murata Y andNishiokaA: Non-surgical care for locally advanced breast cancer: Radiologically assessed therapeutic outcome of a new enzyme-targeting radiosensitization treatment, Kochi Oxydol-Radiation Therapy for Unresectable Carcinomas, Type II (KORTUC II) with systemic chemotherapy. Oncol Rep 24: 1161-1168, 2010.

5. Tokuhiro S, Ogawa Y, Tsuzuki K, Akima R, Ue H, Kariya S and Nishioka A: Development of a novel enzyme-targeting radiosensitizer (KORTUC) containing hydrogen peroxide for intratumoral injection for patients with low linear energy transfer-radioresistant neoplasms. Oncol Lett 1: 1025-1028, 2010 .
6. Hitomi J,Kubota K, Ogawa Y,Hamada N,Murata Y and Nishioka A: Non-surgical therapy and radiologic assessment of stage I breast cancer treatment with novel enzyme-targeting radiosensitization: Kochi Oxydol-Radiation Therapy for Unresectable Carcinomas, type II (KORTUC II). Exp Ther Med 1: 769-775, 2010.

7. Ogawa Y, Kubota K, Ue H, Tadokoro M, Matsui R, Yamanishi T, Hamada N, Kariya S, Nishioka A, Nakajima H, et al: Safety and effectiveness of a new enzyme-targeting radiosensitization treatment (KORTC II) for intratumoral injection for low-LET radioresistant tumors. Int J Oncol 39: 553-560, 2011.

8. Tsuzuki A, Ogawa Y, Kubota K, Tokuhiro S, Akima R, Yaogawa S, Itoh K, Yamada Y, Sasaki T, Onogawa M, et al: Evaluation of changes in tumor shadows and Microcalcifications on mammography following KORTUC II, a new radiosensitization treatment without any surgical procedure for elderly patients with Stage I and II breast cancer. Cancers (Basel) 3: 3496-3505, 2011.

9. Aoyama N, Ogawa Y, Kubota K, Ohgi K, Kataoka Y, Miyatake K, Tadokoro M, Yamanishi T,Ohnishi T, Hamada N, et al: Therapeutic response to a new enzyme-targeting radiosensitization treatment (KORTUC-SC) for patients with chemotherapy-resistant supraclavicular lymph node metastasis. J Cancer Res Ther 1: 215-219, 2013.

10. Aoyama N, Ogawa Y, Kubota K, Yasuoka M, Takahashi M, Iwasa H, Miyatake K, Yamanishi T, Hamada N, Tamura T, et al: Therapeutic response to a novel enzyme-targeting radiosensitization treatment (Kochi Oxydol-Radiation Therapy for Unresectable Carcinomas) in patients with recurrent breast cancer. Oncol Lett 12: 29-34, 2016.

11. Danforth DN Jr, Zujewski J, O'Shaughnessy J, Riseberg D, Steinberg SM, McAtee N, Noone M, Chow C, Chaudhry U, Lippman M, et al: Selection of local therapy after neoadjuvant chemotherapy in patients with Stage IIIA, B breast cancer. Ann Surg Oncol 5: 150-158, 1988.

12. Lorvidhaya V,Kamnerdsupaphon P, Chitapanarux I, Sukthomya V and Tonusin A: Cisplatin and gemcitabine in patients with metastatic cervical cancer. Gan To Kagaku Ryoho 31: 1057-1062, 2004

13. Hu XC,Zhang J,Xu BH, Cai L, Ragaz J, WangZH, Wang BY, Teng YE Tong ZS, Pan YY, et al: Cisplatin plus gemcitabine versus paclitaxel plus gemcitabine as first-line therapy for metastatic triple-negative breast cancer (CBCSG006): A randomized, open-label, multicenter, phase 3 trial. Lancet Oncol 16: 436-446, 2015.

14. Karasawa K, Saito M, Hirowatari H, Izawa H, Furuya T, Ozawa S, Ito K, Suzuki T and Mitsuhashi N: The role of chemoradiotherapy in patients with unresectable T4 breast tumors. Breast Cancer 20: 254-261, 2013.

15. Johnson CJ, Graff R, Moran P, Cariou C and Bordeaux S: Breast cancer stage, surgery, and survival statistics for Idaho's national breast and cervical cancer early detection program population, 2004-2012. Prev Chronic Dis 12: E36, 2015.

16. Mukai H, Watanabe T, Mitsumori M, Tsuda H, Nakamura S, Masuda N, Yamamoto N, Shibata T, Sato A, Iwata H and Aogi K: Final results of a safety and efficacy trial of preoperative sequential chemoradiation therapy for the nonsurgical treatment of early breast cancer: Japan Clinical Oncology Group Study JCORG306. Oncology 85: 336-341, 2013.

17. Yin Y, Zhang $\mathrm{P}, \mathrm{Xu} \mathrm{BH}$, Zhang BL, Li Q, Yuan P, Cai RG, Wang JY, Wang $\mathrm{X}$ and $\mathrm{Xu} \mathrm{XZ}$ : Unfavorable pathological complete response rate of neoadjuvant chemotherapy epirubicin plus taxanes for locally advanced triple-negative breast cancer. J Huazhong Univ Sci Technolog Med Sci 33: 262-265, 2013.

18. Matuschek C, Bölke E, Roth S, Orth K, Lang I, Bojar H, Janni JW, Audretsch W, Nestle-Kraemling C, Lammering G, et al: Long-term outcome after neoadjuvant radiochemotherapy in locally advanced noninflammatory breast cancer and predictive factors for pathologic complete remission: Results of a multivariate analysis. Strahlenther Onkol 188: 777-781, 2012.

19. Genet D, Lejeune C, Bonnier P, Aubard Y, Venat-Bouvet L, Adjadj DJ, Martin J, Labourey JL, Benyoub A, Clavère P, et al: Concomitant intensive chemoradiotherapy induction in non-metastatic inflammatory breast cancer: Long-term follow-up. Br J Cancer 97: 883-887, 2007.

20. Bollet MA, Sigal-Zafrani B, Gambotti L, Extra JM, Meunier M, Nos C, Dendale R, Campana F, Kirova YM, Diéras V, et al: Pathological response to preoperative concurrent chemo-radiotherapy for breast cancer: Result of phase II study. Eur J Cancer 42: 2286-2295, 2006.

21. Shaughnessy JN, Meena RA, Dunlap NE, Jain D, Riley EC, Quillo AR and Dragun AE: Efficacy of concurrent chemoradiotherapy for patients with locally recurrent or advanced inoperable breast cancer. Clin Breast Cancer 15: 135-142, 2015. 